\title{
Integración escolar de un alumno chino: estudio de caso
}

Dimitrinka Níkleva - Universidad de Granada

Noelia Reche Gómez - Universidad de Granada

Recepción: 29.09.2018 | Aceptado: 25.01.2020

Correspondencia a través de ORCID: Dimitrinka Níkleva

Citar: Níkleva, D y Reche Gómez, N (2020). Integración escolar de un alumno chino: estudio de caso. REIDOCREA, 9, 21-51.

Resumen: La llegada de alumnos extranjeros que vienen a centros españoles es un fenómeno que cada día aumenta más, por lo que el sistema educativo español debe ser consciente de lo que esto implica en su labor. El objetivo de este trabajo fue estudiar el proceso de integración de dichos alumnos en las aulas y conocer las medidas que se están aplicando ante esta situación. Se trabajó con un estudio de caso, el cual nos aportó la información necesaria para saber cómo se desenvolvían los docentes del centro donde se realizó el estudio. Damos a conocer tres de los programas que la Junta de Andalucía ofrece, centrándonos específicamente en el aula de apoyo lingüístico: el Aula Temporal de Adaptación Lingüística (ATAL). Es el programa que más se aproxima al objetivo de este estudio al permitir una integración social y académica. La enseñanza del español como lengua vehicular será el punto de partida para que el alumno alcance conocimientos de las áreas curriculares, mostrándolos de forma oral y escrita. Los resultados del estudio afirmaron el desconocimiento de los programas que se mencionan por parte del docente y el alto nivel de integración del alumno. Además, se expone una propuesta de acción, la cual se trabajó como posible forma de acercar al alumno a su máximo nivel de integración.

Palabras clave: Integración escolar

\section{A school integration of a Chinease student: A study case}

\begin{abstract}
The arrival of foreign students in Spanish schools is a growing phenomenon which increases every day, taking this into account the Spanish educational system must realize that this requires special consideration and action on their behalf. The objective of the study was to revise the incorporation process of foreign students inside the classroom and learn about the procedures that are being put into practise in each situation. In this case, the study gave the necessary information to enable us to learn about how the teachers of the educational centre carried out their profession when faced with these situations. In this study we named three of the programmes that the Andalusian council offers, although with the study chosen the most specialized for help inside the language classroom is, 'el Aula Temporal de Adaptación Lingüística' (ATAL). The objective of this study is to allow for a total social and academic integration. The teaching of Spanish as a language that acts as an intermediary will be the starting point to enable the children to learn further curricular areas in both spoken and written form. The results of this study confirmed the lack of awareness on the teachers' behalf surrounding the programmes mentioned, also the high level of integration of the student inside the educational centre. In addition, suggestions were put forward to be set in place to enable the student to reach their highest level of integration possible.
\end{abstract}

Keywords: The school's integration

\section{Introducción}

Actualmente, la llegada de niños de otros países a las escuelas españolas está originando problemas que se ven reflejados en el contexto académico con consecuencias negativas como el fracaso escolar, que a menudo se convierte en un camino hacia la marginación. Como futuros docentes es importante que tengamos conocimientos sobre los interrogantes y sus posibles soluciones. Hemos de conocer: ¿qué ofrece el sistema educativo español a los extranjeros?, ¿cómo se desarrollan las clases con estos? o ¿son los docentes de hoy en día capaces de afrontar la llegada de población extranjera?, ¿se conocen la competencia integradora e inclusiva las aulas?, etc. 
Los datos de algunos estudios internacionales señalan que los resultados académicos de los alumnos extranjeros son inferiores a los pertenecientes de un país, por lo que, según Cebolla (2009), es imprescindible conocer lo que oferta nuestro sistema educativo para poder evitar o, al menos, reducir este problema. Con esto, deberíamos promover la existencia de instrumentos válidos que sepan responder ante la llegada de extranjeros, ya que contamos con un elevado porcentaje de este alumnado $(9,1 \%$ en España) (MECD, 2013). En la figura 1 se puede comparar este dato por comunidades autónomas.

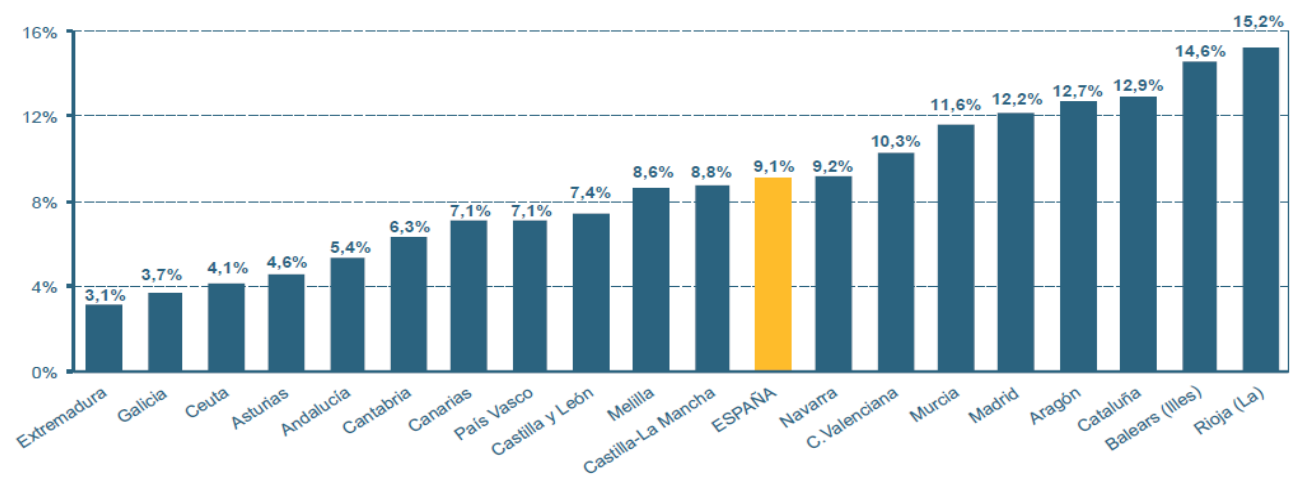

Figura 1. Porcentaje de alumnado extranjero en las enseñanzas no universitarias.

El objeto del estudio es estudiar el proceso de integración de los niños extranjeros en las aulas y conocer las medidas que han funcionado para su integración. También se hará especial mención al apoyo lingüístico que estos alumnos reciben. Además, elaboramos una propuesta práctica para contribuir a la igualdad en el aula.

Se explicará el funcionamiento de una de las medidas que el gobierno español implantó en 1997 en la comunidad autónoma de Andalucía: la primera aula ATAL en Almería.

La metodología de esta investigación es el estudio de caso, porque este método se utiliza para analizar temas o fenómenos actuales, que representan algún tipo de problemática de la vida real. Implica un proceso de indagación mediante el examen sistemático y en profundidad de casos sociales o educativos. Puede incluir tanto estudios de un único caso como de múltiples casos, pero su principal objetivo es comprender las peculiaridades de este.

En esta investigación se hace el estudio de un único caso: un sujeto de nacionalidad china, en el Colegio "Jesús-María Cristo de la Yedra", en Granada. Hemos de añadir que se trata del único sujeto de nacionalidad china entre los casi mil alumnos matriculados en el centro escolar, contando los de Educación Infantil, Primaria y Secundaria.

Las técnicas para recopilar la información necesaria se basaron en dos encuestas para conocer la situación del sujeto seleccionado y varias fichas para el análisis.

El propósito, como ya hemos mencionado anteriormente, es comprobar cómo los niños que llegan a las escuelas españolas se integran en sus aulas y qué medidas están funcionando para que esto se lleve a cabo, en caso de que en el centro no hay aula ATAL.

En la Guía Básica de Educación Intercultural de la Junta de Andalucía (2011) podemos encontrar todos los programas y recursos que se ofrecen a los centros escolares de Andalucía, con el fin de educar en interculturalidad. 
Los programas para afrontar el plurilingüismo y la multiculturalidad en la docencia son:

- Acogida e integración (acogida y mediación intercultural)

- Español con inmigrantes (ATAL, apoyo lingüístico y AVE)

- Cultura de origen (cultura de Origen en actividades escolares y extraescolares y convenios de cooperación con países de origen)

De los programas mencionados vamos a centrarnos en el segundo, ya que es un programa que da acceso a la integración del alumnado extranjero en el centro escolar matriculado y permite que este alumnado se incorpore al nivel que le corresponde según sea su edad y su competencia curricular.

La normativa vigente por la que se regulan las medidas y actuaciones a desarrollar para la atención del alumnado inmigrante y, en especial, las ATAL, se recoge en la ORDEN de 15 de enero de 2007 (BOJA, núm. 33). En dicha Orden se desarrolla este proyecto como un programa de enseñanza y aprendizaje del español, teniendo como objetivo favorecer la integración del alumnado extranjero en los centros escolares.

En otras comunidades autónomas estas aulas de apoyo lingüístico se llaman de distinta forma: aulas de enlace, de acogida, de inmersión lingüística, etc.

Las ATAL se crean en centros públicos, a partir de $3 .^{\circ}$ de Primaria y hasta $4 .^{\circ}$ de ESO, con el requisito de contar con profesionales específicamente para estas aulas, aunque la Orden apunta que todos los docentes deben plasmar en su programación un análisis de la situación inicial y las propuestas de adaptaciones curriculares del alumnado extranjero, incluso deben hacer una valoración del cumplimiento de dichas propuestas.

Esta medida se puede dar tanto en el aula ordinaria, con el resto de alumnos, como fuera de ella, que según Guerrero (2013), aplicar este programa fuera del aula reforzaría la idea de exclusión o segregación en vez de promover la integración. Según especifica la normativa, esto debería darse en casos excepcionales y especiales, pero en la práctica de este programa, la mayoría de los casos son especiales, ya que el apoyo que se recibe suele ser fuera del aula ordinaria (Níkleva, 2014).

Las ATAL han asignado un nivel de acuerdo con el Marco común europeo de referencia para las Lenguas (MCER) (Consejo de Europa, 2002). El alumnado con un nivel lingüístico inferior a B1 tendrá derecho a asistir a estas aulas.

A continuación, se muestra una tabla con la equivalencia entre los niveles lingüísticos según las ATAL y el MCER:

Tabla 1. Equivalencia entre los niveles lingüísticos de las ATAL y del MCER.

ATAL

Nivel 0

Nivel 1

Nivel 2

Nivel 3

\section{MCER}

Categoría anterior al nivel A1: "Ausencia de los conocimientos del español"

A1: presenta nociones del español.

A2: presenta dificultades en lectura y escritura.

B1, B2, C1 y C2: excelentes conocimientos del español.

Respecto al periodo de permanencia en estas aulas, en la actual normativa se establecen 10 horas en Educación Primaria y 15 horas en Secundaria, fuera de las aulas ordinarias. La organización de grupos que acuden a las ATAL no debe superar el número de doce alumnos. 
García et al. (Guerrero, 2013) afirma que en estas aulas no hay igualdad ni integración, sino etnocentrismo cultural, pues existe la opinión de que los alumnos extranjeros tienen dificultades lingüísticas y de adaptación. De ahí, la necesidad de solucionar estos problemas para que sean integrados culturalmente.

Es necesario conocer qué tipo de tareas son convenientes para que su desarrollo a nivel lingüístico progrese en aumento. Por ello, la propuesta de actividades se elabora, teniendo en cuenta el nivel de referencia de español según el Plan curricular del Instituto Cervantes (Instituto Cervantes, 2007).

Uno de los aspectos con mayor importancia es la enseñanza del español como lengua vehicular, es decir, el español va a ser la clave o el instrumento principal para que los alumnos de nacionalidad extranjera puedan alcanzar los conocimientos necesarios de las diferentes áreas curriculares, al igual que tendrán que demostrar esa adquisición de conocimientos, tanto de forma escrita como oral.

¿Los docentes de hoy en día están capacitados para afrontar la llegada de población extranjera? Serrano (1998, p.100) afirma:

[...], el maestro debe ser un 'abridor de mundo', desde sus propias raíces y para la comprensión de la situación de sus alumnos; debe ser capaz de dialogar con los padres de familia y con otros miembros de los grupos locales y convencerlos de las bondades de la modalidad educativa en la que trabaja. Para lograrlo requiere, además de actitud, conocimiento de los dos campos culturales y un saber pedagógico. En cuanto a la de su grupo étnico, conviene insistir en que no basta con vivir en la cultura y hablar la lengua, sino que hay que darse cuenta de ello. De lo contrario, no se podrá ser agente crítico. En este sentido, la formación que recibe afronta el reto de convertirlo en un observador permanente y atento de su propia cotidianidad y la de los suyos, en contraposición a la creencia de que uno no necesita estudiar su cotidianidad porque ya la conoce.

Hay que conseguir que la competencia integradora e inclusiva esté presente en todos los centros escolares, pues a la escuela se va a aprender y para aprender es imprescindible ser integrado por los maestros y por el resto de alumnos.

Para llevar a cabo un estudio del proceso de integración de este alumnado, se puede proceder a un análisis de los componentes culturales, centrándonos en tres grupos siguiendo el Plan curricular del Instituto Cervantes (Instituto Cervantes, 2007):

1. Referentes culturales. Se trata de conocer las condiciones de vida, convenciones sociales o comportamientos rituales, valores o creencias.

2. Saberes y comportamientos socioculturales. Se refieren al comportamiento en relación con la sociedad y la interacción de forma verbal o no verbal. Son imprescindibles para que la comunicación del alumno sea eficaz y rentable.

3. Habilidades y actitudes interculturales. Se trata de capacidades y comportamientos necesarios en situaciones interculturales.

Hemos clasificado estos tres grupos en tres categorías (tabla 2), reduciendo las siete categorías en el estudio de Níkleva (2012):

- Identidad

- Condiciones de vida y organización social

- Interacción social y cultural (comportamientos socioculturales) 


\begin{tabular}{|c|c|}
\hline Categoría & Componentes culturales \\
\hline Identidad & Identidad personal y colectiva. \\
\hline \multirow[t]{7}{*}{ Condiciones de vida y organización social } & Identificación personal. \\
\hline & Familia (concepto y estructura). \\
\hline & Fiestas, ceremonias y celebraciones. \\
\hline & Comida y bebida. \\
\hline & Horarios. \\
\hline & Cultura. \\
\hline & Servicios de mantenimiento de limpieza. \\
\hline \multirow[t]{7}{*}{ Interacción social y cultural } & Relaciones sentimentales, familiares y de amistad. \\
\hline & Relaciones entre clases sociales, generaciones y sexos. \\
\hline & Relaciones con compañeros de trabajo. \\
\hline & Relación con desconocidos. \\
\hline & Interacción no verbal. \\
\hline & Reconocimiento de la diversidad cultural. \\
\hline & Mediación cultural. \\
\hline
\end{tabular}

La identidad se refiere a contenidos como lugar de residencia, clase social, raza, etc.

En cuanto a las condiciones de vida y organización social, hay que destacarlos porque todos los alumnos, extranjeros deben adquirir conocimientos básicos sobre las diferencias con su cultura de origen.

Y por último, en cuanto al grupo de la interacción social y cultural, lo hemos incluido por la importancia que tienen en la sociedad las formas en las que las personas se relacionan con los demás, pues vivimos en una continua comunicación. Para que la comunicación fluya y sea efectiva los alumnos deben estar capacitados para interpretar correctamente tanto la comunicación verbal como la no verbal de sus interlocutores.

\section{Objetivos o hipótesis}

El presente estudio tiene como objetivo principal conocer el proceso de integración de alumnos inmigrantes que viven en la sociedad española, haciendo hincapié en el apoyo lingüístico a través de las medidas que se están aplicando en los centros escolares.

Se han formulado los siguientes objetivos:

1. Conocer las medidas que el sistema educativo español ofrece a la población extranjera.

2. Estudiar el proceso de integración de los alumnos extranjeros.

3. Identificar los referentes culturales, los saberes y comportamientos socioculturales y las habilidades y actitudes interculturales de alumnos extranjeros.

4. Contribuir a la integración del alumnado extranjero a través de una propuesta de acción.

5. Dar a conocer las aulas ATAL.

6. Conocer el tipo de enfoque (inclusivo/segregacionista) con el que se trabaja con el alumnado extranjero en el centro donde se ha realizado el estudio.

\section{Método}

A continuación, se expone la metodología que se ha seguido durante el estudio, incluyendo los participantes que han colaborado, los instrumentos de evaluación y el procedimiento que se ha seguido para el análisis de los datos. 
En primer lugar, para proceder a la obtención de la información se ha realizado una encuesta para conocer la situación del alumno, como ya se ha mencionado anteriormente, de nacionalidad china. Dicha encuesta va dirigida a una tutora profesional del cuarto curso de Educación Primaria, ya que en este curso se encuentra el alumno. La encuesta se dirige a ella, debido a que el alumno tiene algunas dificultades para leer y escribir en español, un nuevo idioma para él.

En segundo lugar, se va a realizar un proceso de observación, a través de una ficha de observación que se va a completar en función de la información que se ha obtenido por medio de la encuesta y además los componentes culturales mencionados anteriormente. El objetivo de esta ficha es observar cómo se integra el alumno en algunas situaciones interculturales que se dan en clase.

Por último, se analizará una encuesta al alumno. La encuesta está escrita en chino para facilitar al alumno y para extraer más información. Durante el proceso de observación, se aplicarán también unas propuestas de acción para contribuir al desarrollo de integración del alumno.

El procedimiento seguido ha tenido una duración de dos meses, con dos horas semanales, asistiendo al aula del alumno tanto en clases de áreas troncales (Matemáticas o Lengua castellana y literatura) como en clases de áreas específicas (Educación física o Educación artística).

Una vez que el tiempo de intervención haya acabado, se realiza un análisis de los datos obtenidos mediante los instrumentos de investigación y partir de ahí, se hace la discusión de los resultados.

\section{Participantes}

El sujeto del estudio de caso es el alumno chino al que nos hemos referido con anterioridad y que estudia en el colegio Cristo de la Yedra.

También participó la tutora académica de este alumno, que hizo posible que este estudio se llevara a cabo. Además del alumno y su tutora, hemos contado también con la colaboración de una intérprete profesional para la traducción escrita de una experiencia que el alumno redactó para este estudio.

\section{Instrumentos}

Los instrumentos de investigación que se han utilizado para el estudio fueron:

- Encuesta.

- Fichas de observación.

- Preguntas, experiencia vivida.

\section{Procedimiento}

En primer lugar se elaboró una encuesta, que fue contestada por la tutora del centro con el fin de conocer la situación del alumno, objeto del estudio, ya que el alumno presentaba pocos conocimientos del español y, además, nos interesaba conocer algunos aspectos importantes que podía aportarla tutora. La encuesta consta de 24 preguntas, que se refieren a las medidas que han aplicado para que el alumno progrese a nivel lingüístico o el tipo de enfoque con el que se trabaja (inclusivo o segregacionista). 
En segundo lugar, se analizaron unas fichas de observación que se completaron asistiendo al aula del alumno, dos horas semanales, para observar si el alumno tenía conocimientos básicos acerca de los referentes culturales, los saberes y comportamientos socioculturales y si era capaz de aproximarse a la cultura española a través de habilidades y actitudes interculturales. Las fichas constan de 20 apartados (anexo 1).

Y por último, se realizó una batería de preguntas redactadas en chino con el objetivo de dar al alumno la oportunidad de poder expresarse en su idioma y escribir su experiencia vivida dentro de su nuevo centro escolar. Las preguntas están relacionadas con el ámbito emocional y cultural, por lo que se pidió al alumno que las llevara a casa para contestarlas con la familia. También de esta forma, se obtuvo más información que si las hubiese contestado él solo (anexo 3).

\section{Análisis de datos}

En este apartado del estudio nos vamos a centrar en el análisis de los datos obtenidos a partir de los distintos instrumentos que se han aplicado. Estos instrumentos se han empleado para realizar un análisis de tipo cualitativo y cuantitativo, por ello vamos a comentar todos los apartados de cada uno de ellos.

\section{Encuesta}

Como ya se ha expuesto en la encuesta, este alumno vive en España desde hace más de dos años y matriculado en el centro durante cuatro meses, por lo que su nivel de español ha mejorado con respecto al momento de su llegada a España. Como bien señala la tutora de este, el nivel es de A1.

En cuanto a las medidas que se han aplicado para el aprendizaje del español como lengua vehicular, hemos de decir que son básicas, de acuerdo con su nivel.

Respecto a las dos preguntas relacionadas directamente con las ATAL, la tutora contesta que no conoce estas aulas y que no tienen una ATAL en su centro escolar.

Se asegura que se ha elaborado una adaptación curricular de Lengua para el alumno.

En cuanto al tipo de enfoque con el que se trabaja con el alumno, hemos de señalar que es inclusivo, porque asiste un maestro de apoyo dentro del aula. Este enfoque además de reducir la exclusión educativa beneficia a todos los alumnos para que aprendan a trabajar juntos, indistintamente de su procedencia, de sus capacidades, de sus condiciones sociales y culturales, etc.

Respecto a las calificaciones medias del alumno son de Aprobado, puesto que cumple con los objetivos que planteados en su adaptación curricular.

Otra de las cuestiones de importancia es si el alumno recibe apoyo lingüístico durante la jornada escolar. La respuesta fue "No", pues, como ya se ha mencionado anteriormente, recibe ayuda para realizar la tarea por parte del maestro de apoyo con más de dos horas semanales, pero no diariamente.

A nivel de integración en el aula por parte de todos, explica la tutora que el primer día de este alumno fue un momento muy esperado y con muchas emociones, pero desde ese día todo volvió a la normalidad y la aceptación por parte de los demás fue buena. 
En cuanto a la forma de comunicación de este alumno con el resto de personas que le rodean en el ámbito escolar, la tutora señala que lo hace hablando en español y por gestos. Cuando está seguro de lo que debe decir, lo hace en español y, por lo contrario, cuando se encuentra en una situación tensa, en la que no es capaz de entender lo que se le pregunta, lo expresa mediante el lenguaje no verbal, es decir, por gestos.

Con respecto a las capacidades personales del alumno, de entre nueve opciones que se daban, la tutora marcó solo una: la capacidad de la inteligencia.

Uno de los factores más importantes para que este alumnado sienta que cuenta con el apoyo familiar es la implicación de esta en el aprendizaje de su hijo o hijos. En este caso, el alumno tiene la ventaja de contar con este factor, según la respuesta de la tutora.

Otra forma que tienen estos alumnos de desarrollar sus habilidades, aumentar el nivel del idioma y, además, incrementar sus relaciones sociales es a través de las actividades extraescolares. Este alumno no asiste a este tipo de actividades, a pesar de que se le aconsejó a la familia que lo hiciera

Por último, al finalizar la encuesta se añadió un apartado de observaciones en el que la tutora aportó datos de especial interés, en el que se verifican algunas de las cuestiones que se han comentado. La tutora redactó lo siguiente:

"El trabajo de este alumno se realiza de la siguiente forma: en matemáticas trabaja los mismos contenidos que el resto de los compañeros (excepto la resolución de problemas). En las asignaturas de ciencias sociales y ciencias naturales la madre le traduce los temas al chino en el mismo libro. En las libretas que tiene para cada área reforzamos la composición escrita y aspectos concretos del área de lengua" [sic].

En cuanto a la resolución de problemas matemáticos es normal que el alumno no pueda trabajarlos igual que el resto de los compañeros debido a la falta de comprensión lectora del idioma. Por otro lado, se muestra la implicación de la familia en el aprendizaje de su hijo, traduciendo el texto al chino. Y, por último, el apoyo escolar se ve reflejado en los cuadernos de trabajo.

\section{Ficha de observación}

Para analizar el proceso de integración del alumno se ha completado una ficha de observación con respuestas dicotómicas de "Sí" o "No".

Para poder valorar su nivel de integración, vamos a mostrar el porcentaje de cada una de las cuestiones que se han observado en este periodo, teniendo en cuenta una tabla que muestra el nivel de cada categoría (identidad, condiciones de vida y organización e interacción sociales y cultural), y dependiendo del porcentaje obtenido se valorará, estableciendo la respuesta "si" como patrón. Por tanto, todas aquellas respuestas con un "Sí", ya sea del $0 \%$ al $100 \%$ se valorarán de la siguiente forma:

- Del $0 \%$ al $33 \%$ - Nivel bajo.

- Del $33,1 \%$ al $63 \%$ - Nivel medio.

- Del $63,1 \%$ al $100 \%$ - Nivel alto.

Pregunta 1: El alumno es capaz de responder con un nivel alto a preguntas básicas relacionadas con su identidad personal (porcentaje de respuestas con un "si" del 100\%) 
Pregunta 2: El alumno sabe perfectamente diferenciar qué saludo debe manifestar en cada momento del día, así como las despedidas. Por lo tanto, el nivel es alto (porcentaje del 100\%)

Pregunta 3: El 22,2\% de las respuestas indican que este alumno tiene un nivel bajo en el inicio de conversaciones con las personas de su entorno escolar, y en su relación con compañeros de clase. Aunque no inicia conversaciones, es importante destacar que siempre intenta entrar en una conversación por gestos o incluso "moviendo la cabeza" para que los demás tengan conocimiento de que él ya está implicado en la conversación.

Pregunta 4: Asistir a las clases de Educación física, al igual que a otras, nos ha ayudado a conocer el porcentaje de interés que muestra el alumno por el juego, aumentando así su relación con los compañeros, tanto en juegos de mesa como en deportivos. Con un $77,8 \%$ el alumno se interesa por el juego; el resto son excepciones cuando el alumno está enfermo. Por consiguiente, su nivel en este aspecto es alto.

Pregunta 5: En cuanto al cumplimiento de las normas expuestas por la clase, el alumno lo hace con un $66,7 \%$. Podríamos decir que el servicio de mantenimiento de limpieza y orden es de nivel alto, a pesar de que no entendía bien lo que se le pedía

Pregunta 6: En esta cuestión el 11,1\% de las respuestas es un "sí". El alumno no expresa sus sentimientos todo lo que se quisiera, pues sus relaciones sentimentales, familiares o de amistad podrían verse afectadas, aunque no es el caso, ya que tanto compañeros como maestros entienden que sus costumbres son muy diferentes a la mayoría y por ello, posiblemente, el alumno muestre una actitud más conservadora. Por ello, en esta cuestión el nivel es bajo.

Pregunta 7: Respecto a las normas de cortesía, este alumno responde con un $77,8 \%$ de veces que sí lo hace. Con ello demostramos que el nivel de relación entre clases sociales, generaciones y sexos es alto.

Pregunta 8: Al igual que la pregunta anterior, esta tiene un alto nivel en la relación con sus compañeros, ya que presenta un $77,8 \%$ en el respeto hacia sus compañeros de clase.

Pregunta 9: Se observa que un $44,4 \%$ de veces el alumno se ha sentado correctamente en su silla, sin dejar que sus relaciones sentimentales, familiares o de amistad se vean implicadas en ningún conflicto.

Pregunta 10: En cuanto a la participación voluntaria para realizar cualquier tipo de actividad, un $22,2 \%$ de veces el alumno lo ha hecho. En la mayoría de las ocasiones que se presentan, este alumno no se interesa en participar ya sea para salir a la pizarra, para leer un texto o para otra tarea, por lo que podría influir en sus relaciones sentimentales, familiares y de amistad, puesto que los compañeros podrían rechazarlo Por esta razón, el nivel es bajo, debido, en parte, al desconocimiento de las actividades que se proponen en clase

Pregunta 11: Respecto a los momentos en el que el alumno presenta "malos" comportamientos, no corrige la mayoría de ellos; en un $22,2 \%$ sí lo hace. Esto quiere decir que su mediación cultural está por debajo de lo esperado, es decir, tiene un nivel bajo.

Pregunta 12: Sin embargo, en esta pregunta el resultado contradice el anterior. Un $77,8 \%$ de respuestas con un "sí", muestra que este alumno es capaz de resolver problemas, reconociendo la diversidad cultural que existe en su aula, por lo que el nivel es alto.

Pregunta 13: Las actividades que son diferentes a la cultura del alumno son de especial importancia e interés para él, pues muestra un $100 \%$ de participación en las mismas, implicándose en las fiestas, ceremonias y celebraciones del país donde reside, por ello el nivel es alto. 
Pregunta 14: En cuanto a la falta de confianza que el alumno presenta, un $66,7 \%$ expresa que muestra falta de confianza tanto hacia él mismo como hacia los demás compañeros, ya que se encuentra en una situación en la que tiene una relación con desconocidos para él, de modo que el nivel es alto.

Pregunta 15: Respecto a la interacción no verbal de este alumno, se muestra que mantiene mucha distancia con los interlocutores en una conversación con un $77,8 \%$. Por tanto, el nivel es alto.

Pregunta 16: El alumno, en la mayoría del tiempo, no se encuentra solo, excepto en mínimas ocasiones en las que ha tenido algún conflicto. El porcentaje con un "sí" es de un 22,2\% y demuestra un nivel bajo en identidad colectiva.

Pregunta 17: La comunicación del alumno con sus maestros en cuanto a la información que él mismo da es bastante buena, ya que presenta un $100 \%$, lo cual significa que su relación entre clases sociales, generaciones y sexos es alta.

Pregunta 18: Respecto a las preguntas que se plantean en clase, un $11,1 \%$ de las veces el alumno responde a ellas, probablemente no lo hará siempre por el temor a equivocarse (cuestión que corroboran las pregunta 3 y 14). Por tanto, el nivel es bajo.

Pregunta 19: En cuanto a la forma de comunicarse o de aceptar nuevas experiencias, lo hace expresándolo en su idioma y su cultura, ya que en un $77,8 \%$ domina los contenidos del apartado sobre cultura. Por tanto, su nivel de integración en este aspecto es alto.

Pregunta 20: Y, por último, la mayoría de las veces, con un $77,8 \%$, este alumno intenta buscar una solución para poder formar parte de un grupo, fomentando así su relación con los compañeros de clase. Por ello, el nivel es alto.

A continuación, mostramos algunos de los resultados de la observación con gráficos

*P1 (Pregunta 1), P2 (Pregunta 2), P3 (Pregunta 3), etc. 


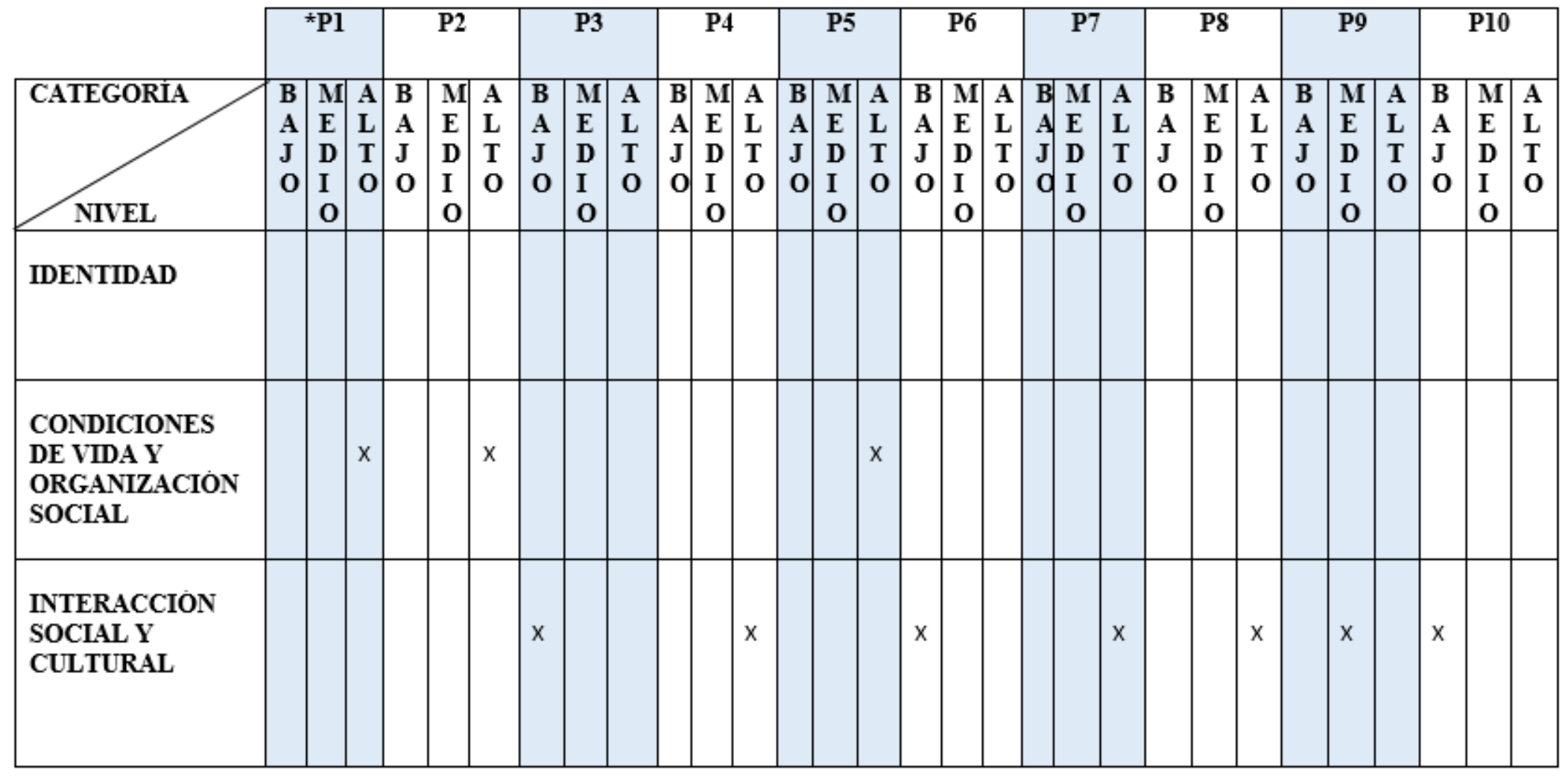




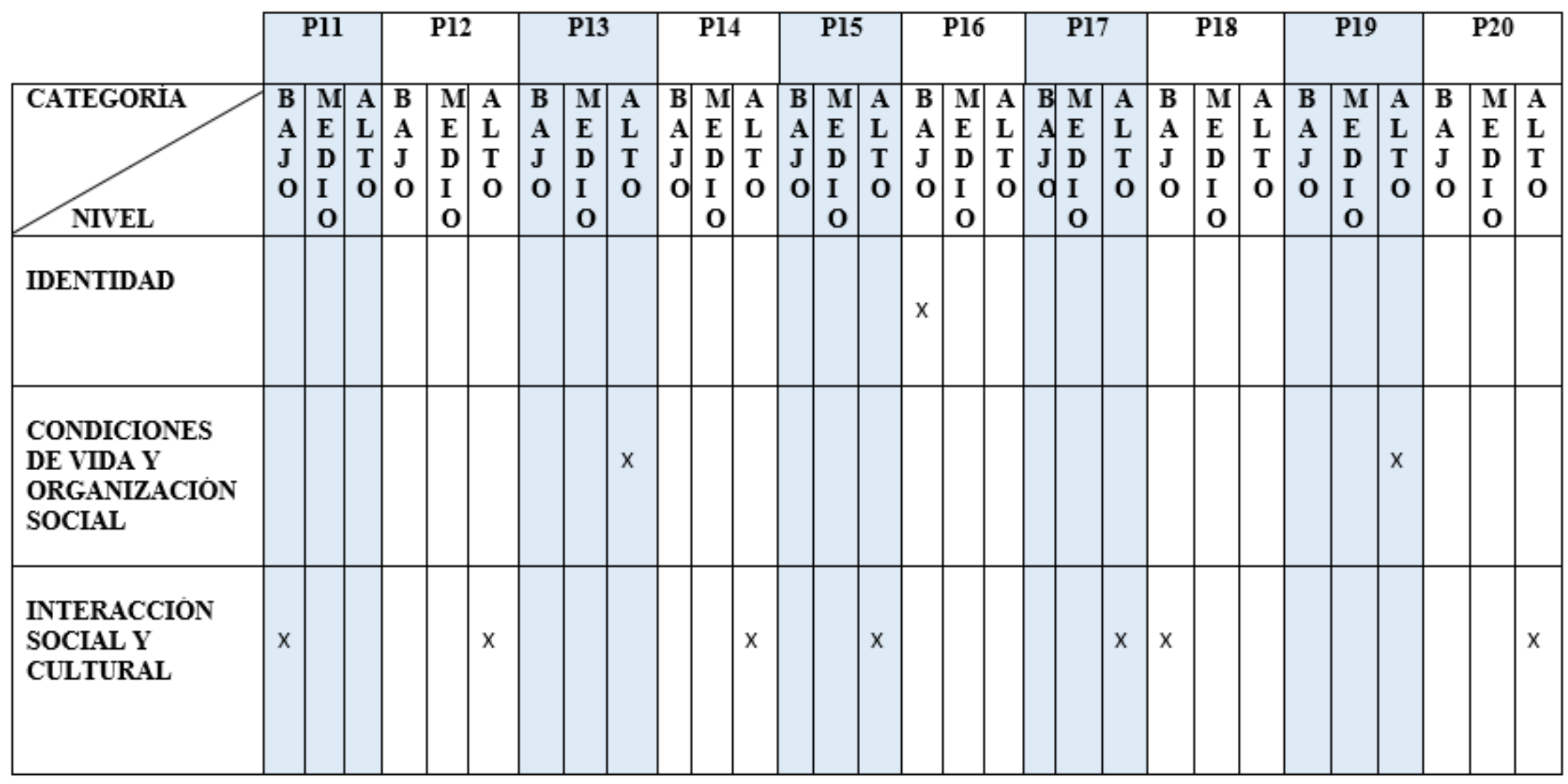




\section{Experiencia vivida (ver anexo 3)}

Por último, se muestra un breve comentario de algunas de las respuestas formuladas en chino y de especial interés para el objeto de estudio, Nos vamos a centrar en las preguntas $3,4,6,11$ y 12 .

Pregunta 3: En esta primera pregunta observamos que sus afirmaciones tan convincentes no dejan duda de que este alumno tiene una muy buena relación con sus compañeros de clase. Ellos siempre intentan que el alumno se sienta, a nivel emocional, lo más cómodo posible, ayudándolo y dándole ánimos para que él mismo se sorprenda de lo que realmente es capaz de realizar.

Pregunta 4: Esta pregunta no tuvo ninguna respuesta. La cuestión estaba relacionada directamente a cómo se sentía en su clase y lo que necesitaba para estar mejor, cuestión realmente importante para el estudio. Para poder obtener una respuesta a esto, se asistió al aula del alumno para que nos diera una explicación y él contestó: "No, no quiero", es decir, no quería responder. Más tarde se le explicó al alumno que necesitábamos conocer su respuesta para ayudarlo y, al día siguiente, nos dio la respuesta (adjunta a continuación).

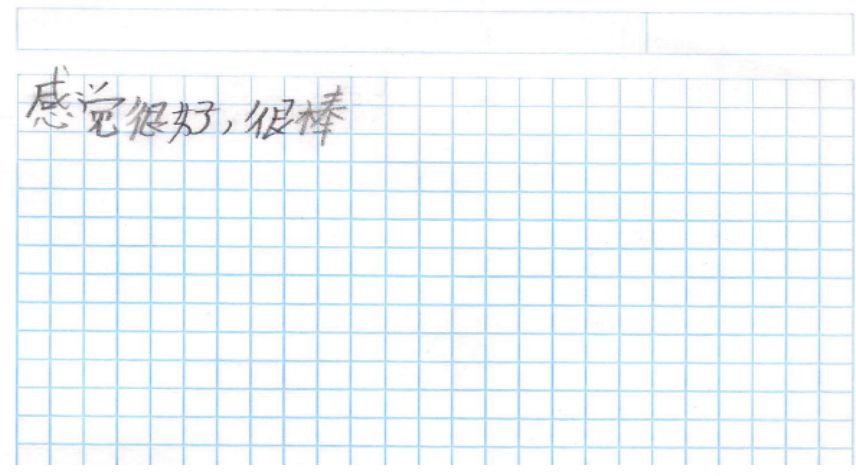

Traducción:

"Me siento muy bien, genial".

El acto de no contestar a esa pregunta en la primera oportunidad que tuvo nos hace pensar que el alumno no se siente bien a nivel emocional cuando está en clase.

Pregunta 6: En cuanto a la pregunta de la dificultad del idioma, el alumno contestó que no es difícil y lo más relevante fue su argumento. Nos respondió que no era difícil, ya que la profesora estaba siempre muy atenta a él. En definitiva, podemos afirmar que esta tutora, se implica tanto en el aprendizaje como en la integración del alumno.

Pregunta 11: Respecto a la participación de actividades en la escuela, el alumno contestó que él solo no podía hacerlas. Sin embargo, la cuestión 10 nos confirma que el alumno está muy interesado en la participación de estas y, por supuesto, que le gusta llevarlas a cabo. Por lo tanto, concluimos que el alumno se preocupa por la participación de actividades y, para ello, necesita la ayuda de alguien.

Pregunta 12: La respuesta a esta pregunta fue "No me gusta", es decir, que no le gusta trabajar en grupo. El alumno demuestra ser más independiente, pero para poder ayudarlo es necesario que se deje "proteger" para fomentar su participación a nivel de grupo. 


\section{Propuestas de acción}

Durante el proceso de observación, se llevan a la práctica unas propuestas de acción que se han aportado para mejorar y cooperar por la integración del alumno a través de la asignatura de Lengua Castellana y Literatura.

La propuesta está pensada para trabajarla en esta asignatura, ya que es un área fundamental para que el alumnado extranjero mejore y aumente su nivel de español y, al mismo tiempo, tenga la oportunidad de relacionarse con sus compañeros y maestros, fomentando su integración. También se podría trabajar con el resto de las materias siempre y cuando se adapten a las mismas.

El principal objetivo de estas propuestas es lograr el máximo nivel de integración de los alumnos extranjeros en las aulas.

Las propuestas de acción que hemos elaborado son tres:

- El teatro

- Cuentos con viñetas

- Bingo de palabras

El teatro, una herramienta más en el aula, es una actividad que da acceso al desarrollo de múltiples habilidades que posiblemente el niño desconocía y no había descubierto antes. El teatro aporta unos beneficios a cada uno de los alumnos tanto extranjeros como nativos o con necesidades especiales, pues aumenta la expresión verbal y corporal, la relación con los compañeros, la seguridad y confianza en ellos mismos, etc.

Los cuentos con viñetas o ilustraciones, una forma para dejar llevar la imaginación del alumno con total libertad para que él mismo sea el propio autor de su cuento. Por medio de unas simples ilustraciones podemos hacer que los alumnos las interpreten, las ordenen de la forma que ellos deseen hasta llegar a expresarlas con palabras y conseguir una historia como resultado.

El bingo es un juego de azar muy popular que normalmente se juega con números, pero nosotros lo hemos modificado y hemos planteado el bingo de palabras. Es una propuesta con la que a través del juego todos los alumnos se divierten y, además, el alumnado extranjero se integra, aportando la traducción de las palabras en su idioma, lo que resulta divertido para sus compañeros. Se trabajan algunos aspectos que están muy relacionados con la atención, la concentración, el lenguaje oral, etc.

\section{Resultados}

Se trabaja con el enfoque inclusivo dentro del aula para ayudar en tareas relacionadas con las diferentes áreas de conocimiento.

En este sentido, son interesantes los resultados de un estudio relativamente reciente del 2014/2015 que la Dirección General de Participación y Equidad solicitó con el objetivo de conocer el grado de satisfacción del profesorado en las ATAL, del alumnado en estas aulas y de sus familias, con la finalidad de introducir las mejoras pertinentes (Agencia Andaluza de Evaluación Educativa, 2015). Con el objetivo de estudiar qué enfoque -inclusivo o segregacionista- predomina en la práctica se hizo la siguiente pregunta: ¿Asistes al aula de español (ATAL) separado de tu grupo? Las opciones de respuesta fueron "Sí" y "No". Un 9,1\% del alumnado encuestado recibe la atención en 
el aula ordinaria y un $90,9 \%$ lo hace en grupos de apoyo fuera del aula ordinaria. Este resultado revela que en la práctica predomina el enfoque segregacionista, el no recomendado por la Orden de 15 de enero de 2007 que regula el funcionamiento de las ATAL. Pero es muy importante el dato que aportan los propios alumnos: un $76 \%$ de este alumnado no está de acuerdo o está poco de acuerdo con que se realice la atención en el aula ordinaria.

A través de las fichas de observación se ha visto claramente que el alumno tiene un nivel muy alto de integración y que, por lo general, se encuentra cómodo en su ambiente (afirmación que coincide también en las respuestas escritas en chino).

\section{Discusión}

El análisis de datos y los resultados conllevan unas conclusiones que resumimos en este apartado.

En primer lugar, debemos resaltar la importancia que tiene la preparación académica de los docentes al igual que su continua formación, pues la población extranjera ha aumentado en estos últimos años y, por lo tanto, estos alumnos tienen derecho a una educación digna como todos.

En segundo lugar, pretendemos destacar la necesidad de recibir apoyo lingüístico en la escuela, ya sea con contenidos académicos o a través del juego, pues es un modo de aprender español. La enseñanza del español como lengua vehicular va a dar paso al éxito del aprendizaje a nivel académico y a nivel integrador.

Y en tercer lugar, nos parece importante reconocer el trabajo que se hace día a día con este alumno en concreto, ya que según lo analizado y observado, el proceso de integración de este alumno es de un nivel bastante alto.

Por último, queremos finalizar con una imagen que sintetiza el fin de este estudio, una imagen dedicada a todos los maestros que ejercen su profesión y a todos aquellos que están en proceso de ejercerla.

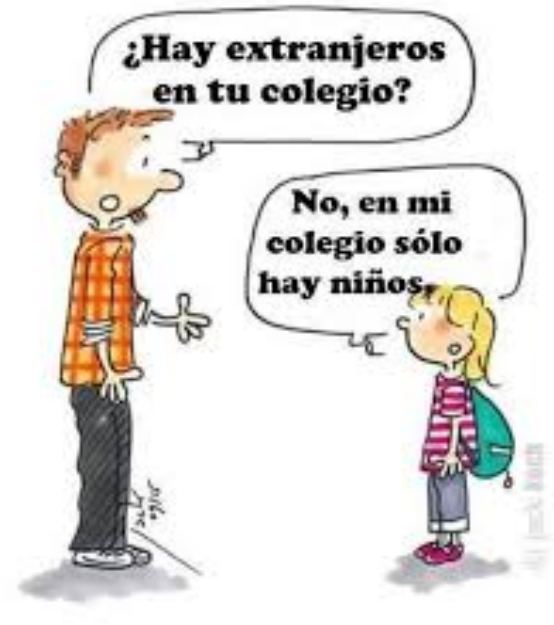

Fuente: https://bit.ly/2NBIz73 


\section{Referencias}

Agencia Andaluza de Evaluación Educativa (AGAEVE) (2015). Estudio sobre la organización y el funcionamiento de las Aulas Temporales de Adaptación Lingüística (ATAL). Sevilla: Consejería de Educación de la Junta de Andalucía.

Calvo, M (2007). ¿Qué ofrece la escuela pública española a los inmigrantes? Nueva revista de política, cultura y arte, 113, s/p.

Cebolla, H (2009). La concentración de inmigrantes en las escuelas españolas. ARI, pp. 1-9.

Consejo de Europa. (2002). Marco Común Europeo de Referencia para las Lenguas.

Guerrero, RM (2013). Integración sociocultural y enseñanza del español en Andalucía Aplicación del programa Aulas Temporales de Adaptación Lingüistica (ATAL). Perfiles Educativos, 35 (142), 42-53.

Junta de Andalucía. Consejería de Educación. (2011). Guía Básica de Educación Intercultural.

Junta de Andalucia. Consejería de Educación. Orden de 15 de enero de 2007, BOJA, de 14 de febrero de 2007, núm. 33.
Ministerio de Educación, Cultura y Deporte. (2013). Datos y cifras educación.

Níkleva, DG (2012). La competencia intercultural y el tratamiento de contenidos culturales en manuales de español como lengua extranjera. RESLA, 25, 165-187.

Níkleva, DG (2014). La formación del maestro para las Aulas Temporales de Adaptación Lingüística (ATAL): una propuesta de ajustar la formación académica y la demanda laboral. En D. G. Níkleva (Ed), El reto de atender a alumnos inmigrantes en la sociedad española (pp. 15-44). Madrid, España: Síntesis.

Pressler, M (1990). Solo hay que atreverse. Madrid: Espasa-Calpe.

Serrano, J (1998). El papel del maestro en la Educación Intercultural Bilingüe. Revista Iberoamericana de Educación, 17, 100.

Zapico, L y Prado, E (2007). Enseñanza del Español como Lengua Vehicular a Alumnos Inmigrantes. Madrid, España: CEP 


\section{Anexos}

\section{Anexo 1. Datos obtenidos de la ficha de observación}

A continuación, presentamos los datos obtenidos en el período de observación:

1. Contesta preguntas personales básicas ("¿cómo te llamas?, ¿cuáles son tus apellidos?, ¿dónde vives?, etc."):

(9 respuestas)

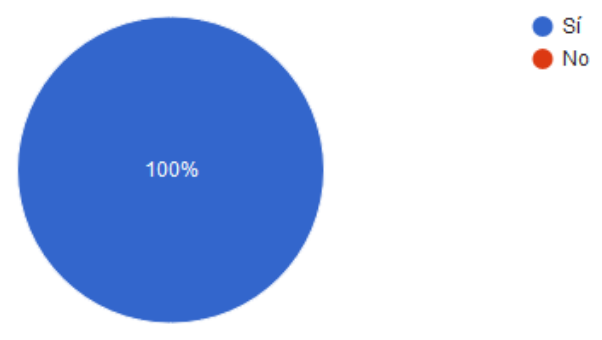

2. Hace un uso correcto de los saludos y las despedidas según el momento y la situación del día ("buenos días, buenas tardes, adiós, etc."):

(9 respuestas)

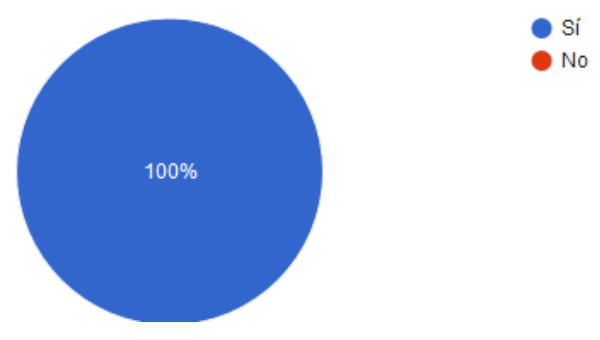


3. Inicia conversaciones con los adultos y con los compañeros ("pide el turno de palabra, pregunta cuando no entiende, pide explicaciones, etc."):

(9 respuestas)

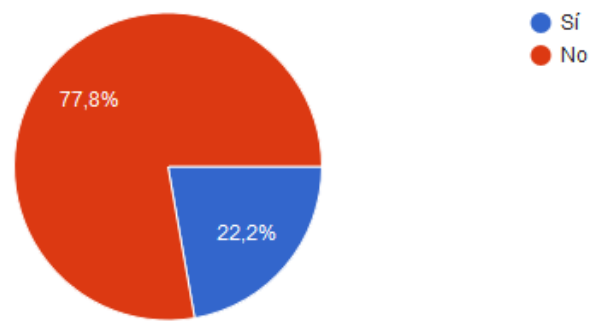

4. Muestra interés en participar en juegos y/o deportes colectivos ("juegos de mesa, pies quietos, fútbol, baloncesto, etc."):

(9 respuestas)

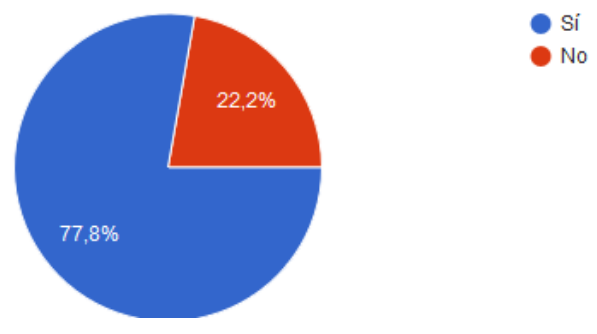

5. Cumple con sus obligaciones cuando es debido ("guarda su material, ordena la mesa, reparte libros, etc."):

(9 respuestas)

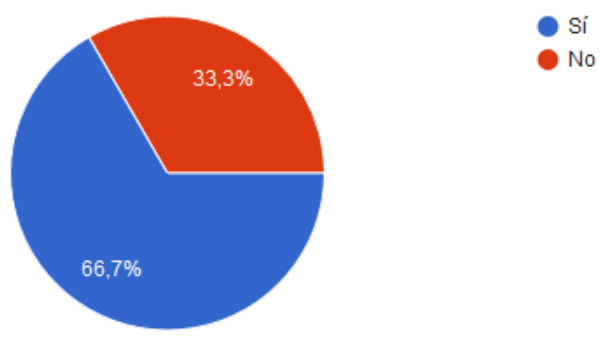

6. Muestra cariño hacia sus relaciones sentimentales ("amistades, familiares, maestros, etc."):

(9 respuestas)

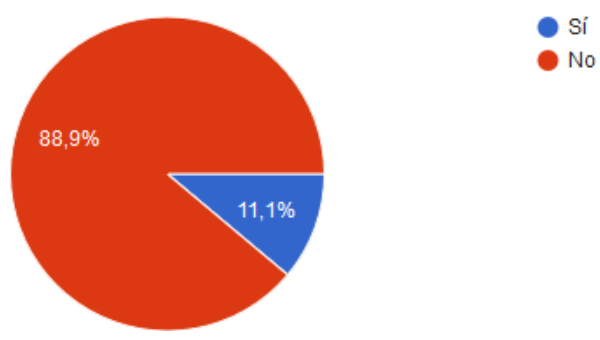


7. Respeta las normas de cortesía en el trato con sus mayores ("agradecimiento, disculpas, etc."):

(9 respuestas)

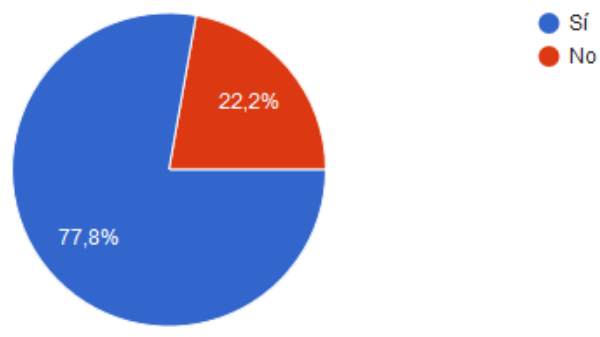

8. Respeta a sus compañeros de clase ("coge el material pidiendo permiso, no es violento con ellos, no se burla de ellos, etc."):

(9 respuestas)

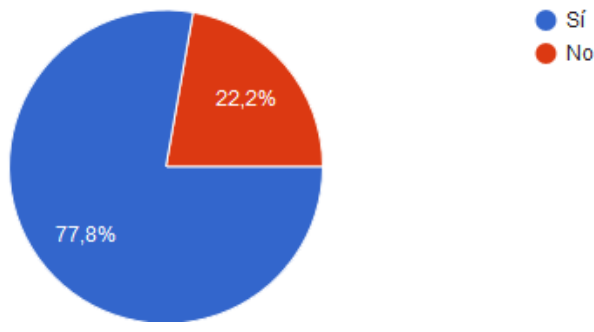

9. Se muestra activo, manteniendo una postura correcta en clase ("bien sentado"):

(9 respuestas)

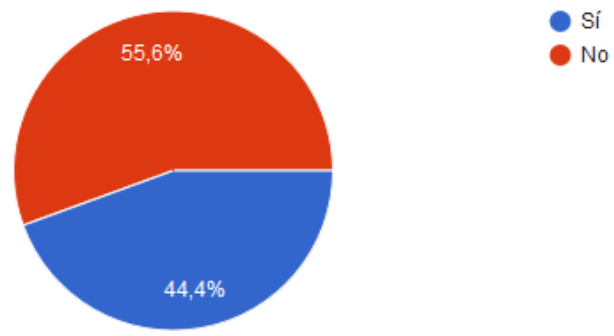

10. Participa voluntariamente en actividades que se proponen en clase ("leer, salir a la pizarra, corregir actividades, etc."):

(9 respuestas)

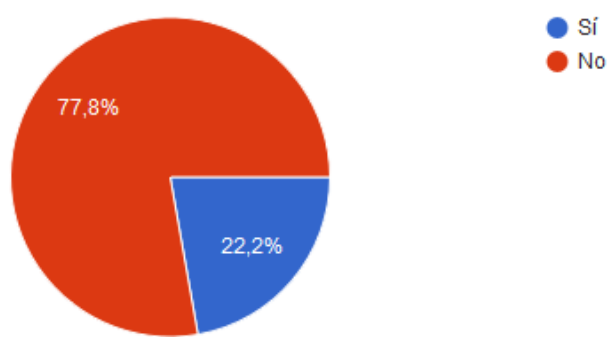


11. Corrige sus actos ante un mal comportamiento hacia los compañeros o maestros ("pide perdón, asume su culpa, se arrepiente, etc."):

(9 respuestas)

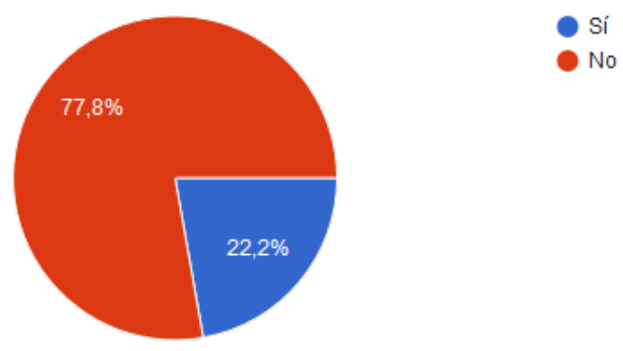

12. Resuelve problemas valorando las diferencias culturales ("tolera las formas de solucionar un conflicto, acepta la formación de una fila o cola, aprecia la relación del maestro-alumno, etc."):

(9 respuestas)

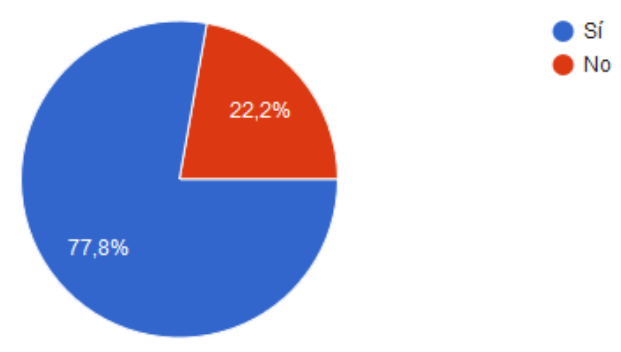

13. Participa en actividades diferentes a su cultura ("celebración de la semana cultural, del día del padre o de la madre, día del libro, etc."):

(9 respuestas)

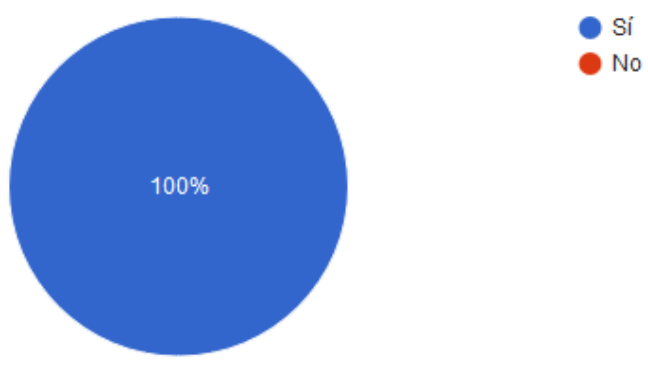


14. Muestra falta de confianza hacia sí mismo y hacia los demás ("no le gusta que vean su letra, se avergüenza al hablar, no presta material, etc."): (9 respuestas)

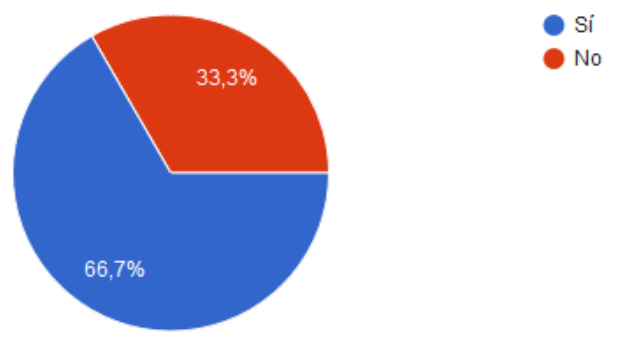

15. Mantiene mucha distancia con los interlocutores: (9 respuestas)

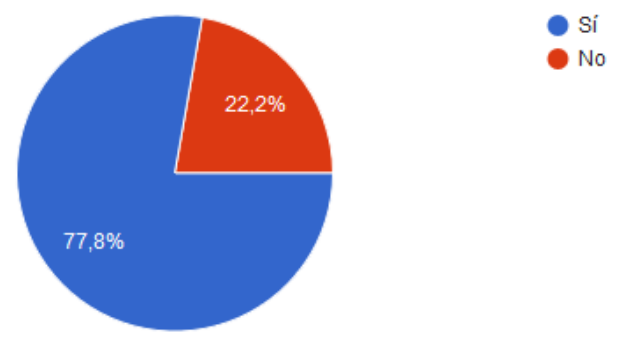

16. Aparenta sentirse solo respecto a su grupo: (9 respuestas)

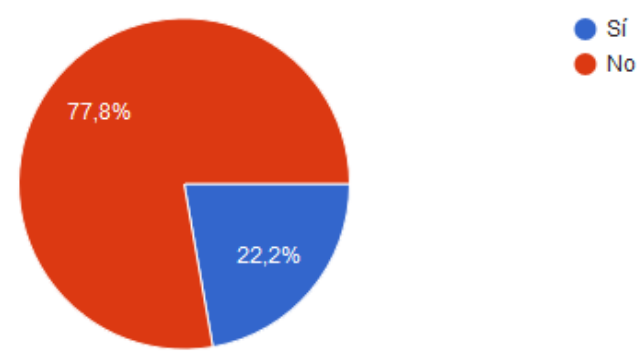

17. Informa al maestro cuando tiene necesidades ("beber agua, ir al baño, estar enfermo, etc."):

(9 respuestas)

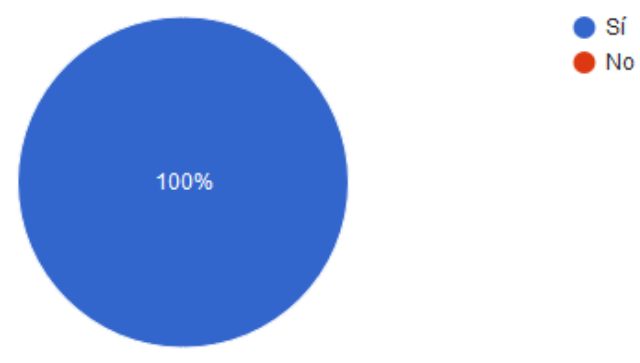


18. Contesta preguntas que no son directas hacia él ("preguntas que se hacen para todos los alumnos"):

(9 respuestas)

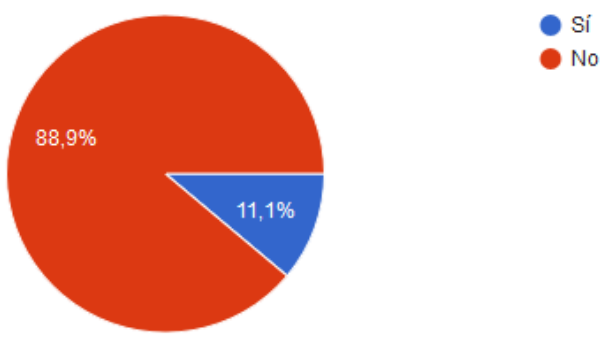

19. Se apoya en su idioma y en su cultura para comunicarse, pensar o admitir nuevas vivencias:

(9 respuestas)

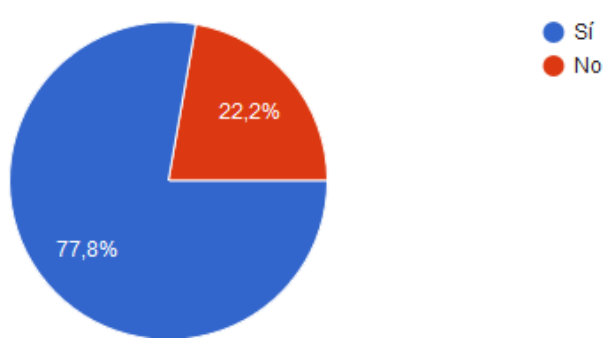

20. Intenta buscar soluciones para unirse a un grupo de personas para realizar trabajos ("preguntando, consultando con sus compañeros o maestro, etc."):

(9 respuestas)

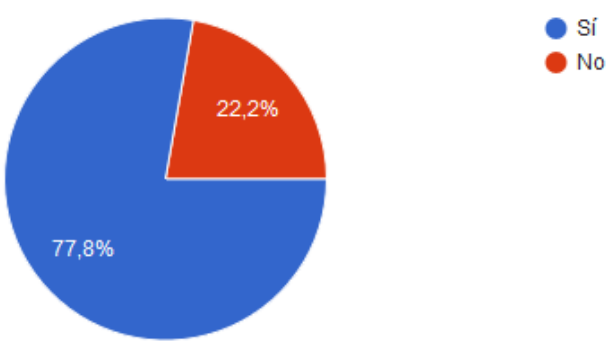


Anexo 2. Actividades en las propuestas de acción

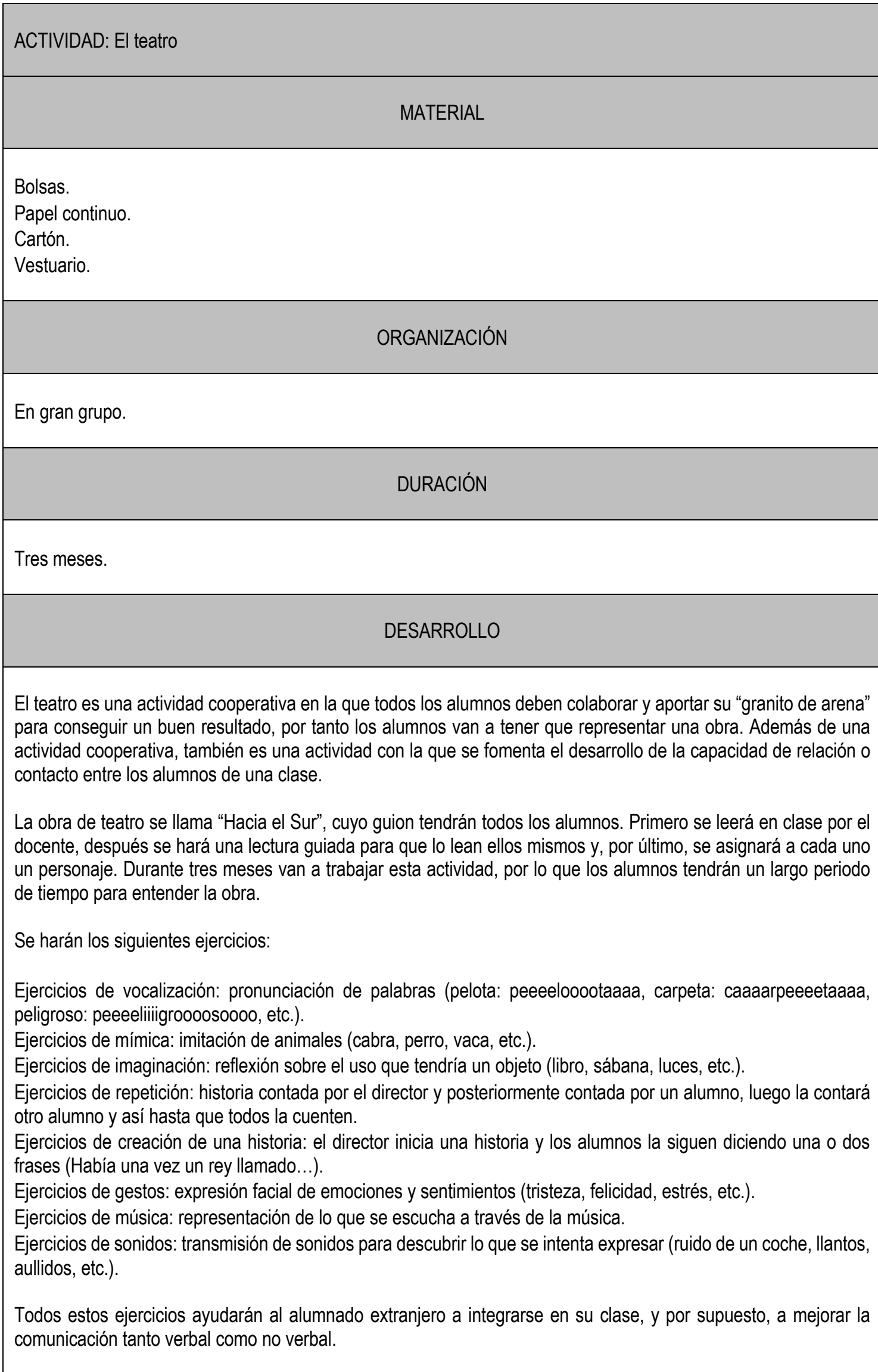


Una vez que los ejercicios se practiquen a diario y se hagan ensayos para la obra principal, la presentan ante público.

REPRESENTACIÓN GRÁFICA

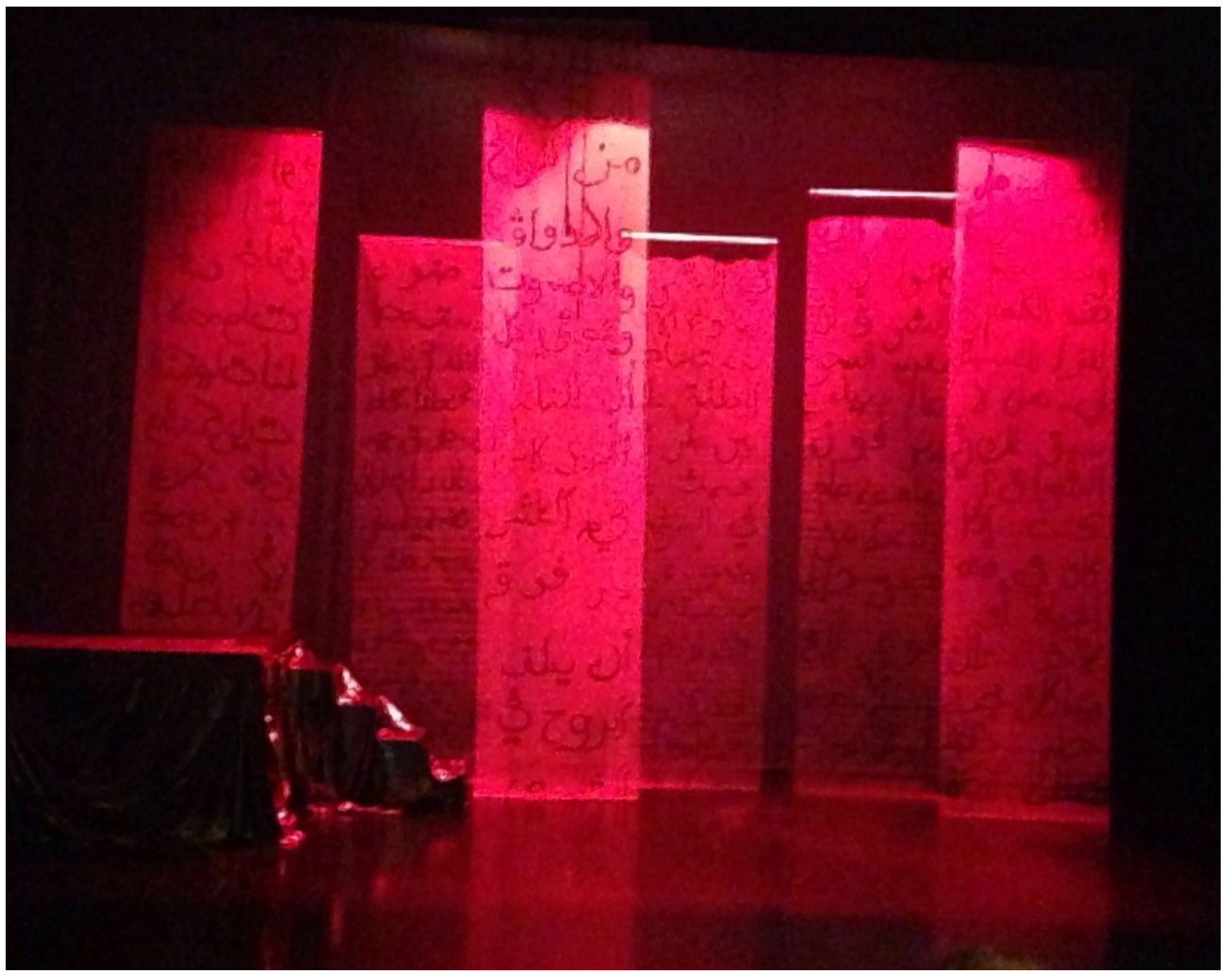

ACTIVIDAD: Cuentos con viñetas

MATERIAL

Fichas con viñetas.

ORGANIZACIÓN

En grupos de 4.

DURACIÓN

45 minutos.

DESARROLLO 
Para trabajar con el cuento se va a proporcionar a cada grupo una ficha con unas viñetas desordenadas que contienen alguna información. Cada grupo ordenará las viñetas e inventará una historia que más tarde contará al resto de compañeros. Todos van a tener las mismas viñetas para saber cuántas historias diferentes hay.

La historia debe ser clara y sencilla. Las viñetas, una vez que estén ordenadas, se van a pegar en una cartulina y debajo de cada viñeta deben escribir las frases o párrafos de la historia.

Para guiar a los alumnos se aconsejará que para que un cuento esté bien estructurado y organizado es necesario seguir algunas pautas:

Título.

Presentación.

Desarrollo.

Conflicto.

Desenlace.

Además de la estructura del cuento, también ofreceremos el comienzo de algunas frases para que ellos puedan continuar con la historia:

Había una vez...

Hacía unos años...

En un lugar muy lejano...

De repente...

Inesperadamente...

De pronto...

Finalmente...

Así fue como...

Etc.

El alumnado extranjero aprenderá a trabajar en equipo, ya que en esta actividad se necesitará tanto su opinión como la de los demás compañeros para hacer posible que su cuento sea lo más creativo posible. 


\section{MATERIAL}

Pizarra digital.

Cartones de bingo.

Imágenes con palabras.

Lápices.

ORGANIZACIÓN

Por parejas.

DURACIÓN

45 minutos.

DESARROLLO

El docente muestra en la pizarra digital, de forma aleatoria, imágenes con sus respectivos nombres y los alumnos tienen que marcar con una cruz $(X)$ las palabras que aparezcan en sus cartones. Cuando una pareja haya marcado una línea horizontal completa debe cantar "iLÍNEA!". Para comprobar que la línea es correcta uno de ellos o ambos deben decir en voz alta al maestro todas las palabras de esa línea y si es errónea, deben continuar hasta que otra pareja cante una línea correcta. Si la línea que se ha cantado es correcta, el maestro continuará mostrando imágenes con sus nombres hasta que una pareja cante "¡BINGO!" al completar todo el cartón. Se realizará la misma operación anterior para comprobar que el bingo es correcto. En este juego habrá dos líneas y un bingo para hacerlo más emocionante.

Las palabras estarán relacionadas con un ámbito, es el ámbito escolar, por lo que las palabras van a ser:

Alumno

Bolígrafo

Calendario

Colores

Compás

Cuaderno

Estuche

Goma

Lápiz

Libro

Maestro

Mapa

Mochila

Ordenador

Papelera

Pizarra

Regla

Sacapuntas

Tijeras

Tizas 
Una vez que se haya comprobado el bingo, el alumnado extranjero debe salir a la pizarra para escribir en su idioma las palabras que tenía en su cartón de bingo para brindar al resto de compañeros la oportunidad de conocer palabras en otros idiomas.

Como curiosidad se da la opción de escribir el nombre de todos los alumnos en ese idioma.

\section{REPRESENTACIÓN GRÁFICA}

BINGO DE PALABRAS.




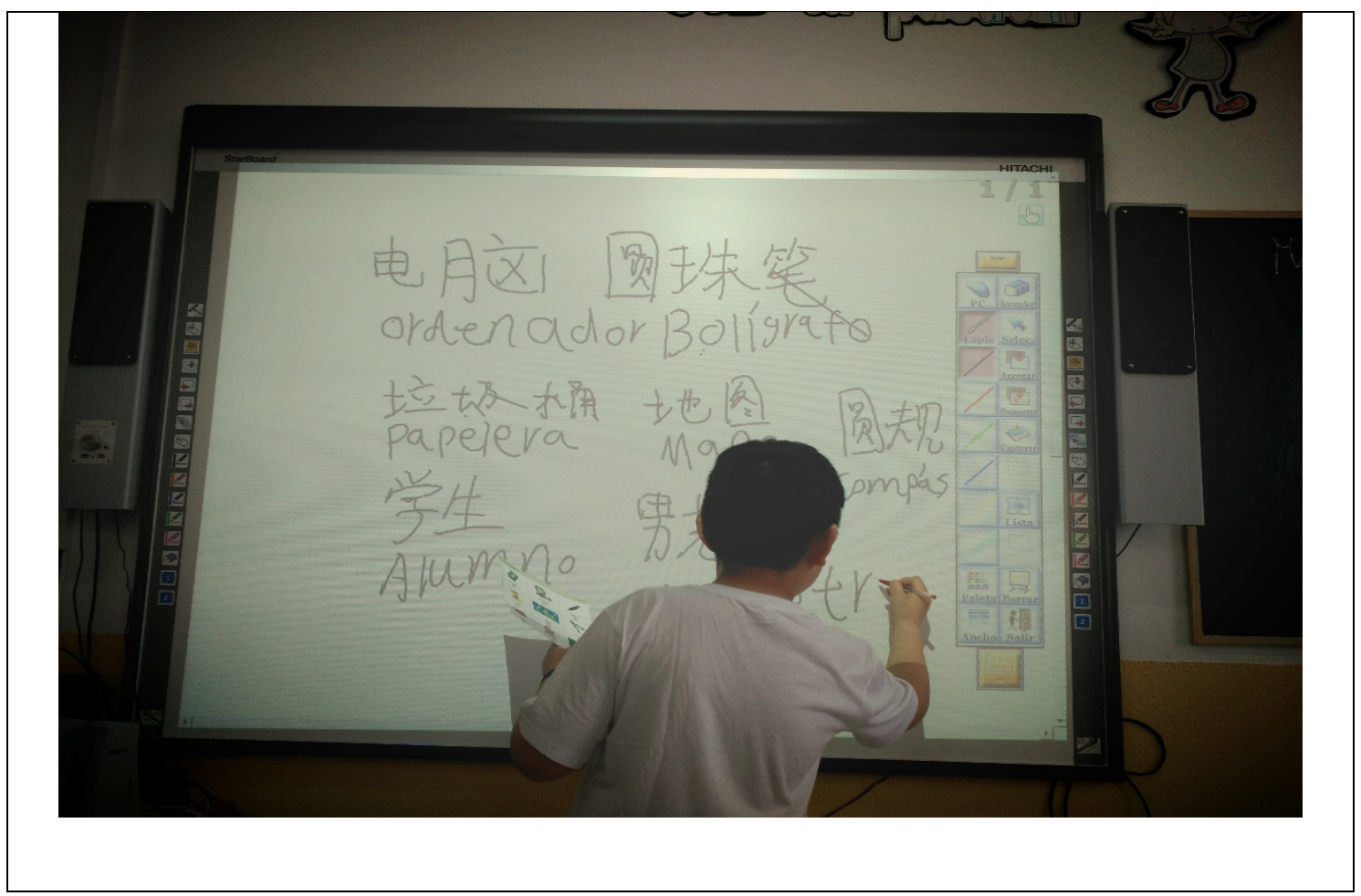

Anexo 3. Experiencia vivida

生活经验

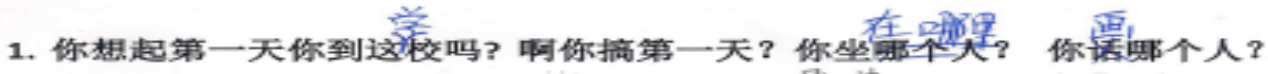
是 111 月12号 最靠近 讲空的地的

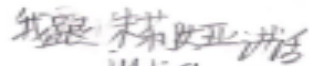
julia

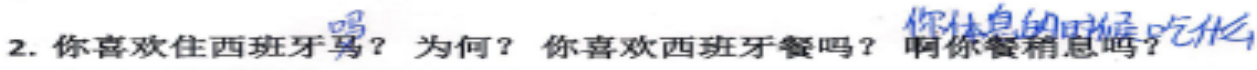
喜欢因为很舒䏜 喜欢然抅、焻、面包片面岜

3. 你有没有朋友你的教室? 他们是好不好? 他们与你辎你的习题吗? 你能不能玩跟他们?

$$
\text { 有对我很好有我抲跟多煺们玩 }
$$




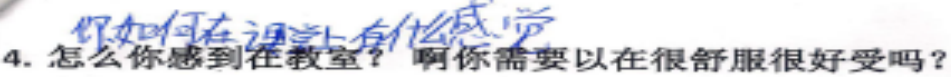

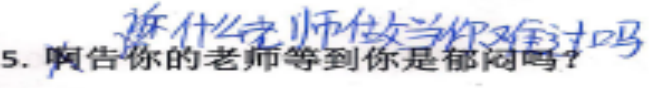

$$
\text { 没有 }
$$

6. 你想西班牙语是难? 为何?

$$
\text { 好学, 由为用心学就可以了 }
$$

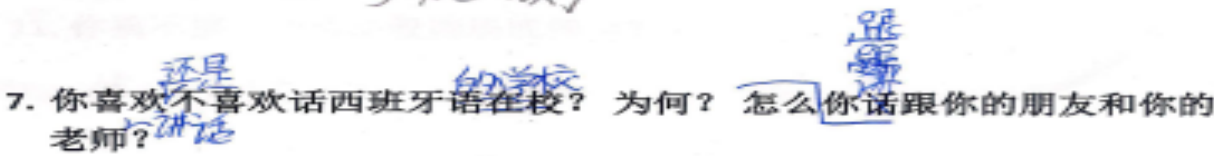

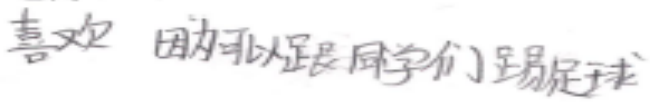

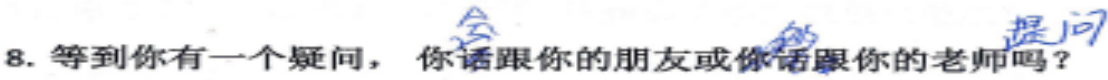

$$
\text { 会 }
$$

9. 区别西班牙校和中国校。

臹动元，小学中学在一起的

10. 你喜欢掊西班牙活动吗? 你想活动是不是有趣? 为何? 喜欢因为可以玩有趣

11. 你搞不搞一个活动般剧场或舞会?

$$
\text { 我一个人搞不了 }
$$

12. 你喜欢工作群吗? 你能不能拉羁你的朋友以但议想法?

$$
\text { 不壱皮 }
$$


13. 那些是你的中国名字? 你有没有西班牙名字? 为何? 周航宇

14. 什么时候是新年?

27/1)

\section{Traducción:}

1. ¿Te acuerdas del primer día que llegaste al colegio? Escribe qué hiciste ese día, con quién te sentaste, con quién hablaste, etc.

- Llegué el día 12 de diciembre.

- Me senté muy cerca de la profesora.

- Hablé con Julia.

2. ¿Te gusta vivir en España? ¿Por qué? ¿Te gusta la comida española? ¿Qué traes para desayunar en el recreo?

- Me gusta vivir en España porque es muy cómodo.

- Me gusta la comida española.

- Traigo algo caliente, fruta o rebanadas de pan (bocadillo).

3. ¿Tienes amigos en tu clase? ¿Son buenos compañeros? ¿Por qué? ¿Te ayudan con la tarea? ¿Te dejan jugar con ellos?

- Sí.

- Sí, muy buenos compañeros.

- Sí, ellos me ayudan.

- Sí, puedo jugar con ellos.

4. ¿Cómo te sientes en clase? ¿Qué necesitas para sentirte mejor y más cómodo en clase?

- *Pregunta sin respuesta

5. ¿Qué hacen los maestros cuando te sientes desanimado o triste?

- $\quad$ No me siento triste ni desanimado.

6. ¿Crees que el español es un idioma difícil? ¿Por qué?

- No, porque la profesora es muy cuidadosa en el colegio y pone mucha atención.

7. ¿Te gusta hablar en español cuando estas en el colegio? ¿Por qué? ¿De qué forma te comunicas con tus compañeros o maestros?

- Sí, me gusta.

- Puedo hablar con los profesores y con los compañeros.

8. Cuando tienes un problema, ¿hablas con el compañero o con el maestro?

Con todos, en conjunto. 
9. ¿Qué diferencias hay entre el colegio de España y el colegio de China?

- En España la guardería, primaria y secundaria está todo junto, en China están separados.

10. ¿Te gusta participar en actividades diferentes a tu país? ¿Te parecen interesantes y divertidas las actividades? ¿Por qué?

- Sí, me gustan.

- Me interesan.

- Porque puedo jugar.

11. ¿Has participado en alguna actividad como teatro 0 baile?

- Yo solo no puedo hacerlo.

12. ¿Te gusta trabajar en grupo? ¿Te pones de acuerdo con tus compañeros para proponer ideas u opiniones?

- $\quad$ No me gusta.

13. ¿Cuál es tu nombre chino? ¿Tienes nombre español? ¿Por qué?

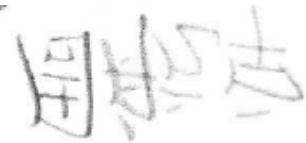

- No tengo

14. ¿Cuándo es año nuevo?

- Febrero. 